\title{
Learners' Identity Through Soundscape Composition: Extending the Pedagogies of Loris Malaguzzi With Music Pedagogy
}

Matthew Yanko

\begin{abstract}
It is astonishing to observe, listen, and co-learn with children as they engage with music to expand beyond the possible with their meaning-making abilities-immersing themselves in a hundred languages of music inspired by Loris Malaguzzi. In the current study, I examine how children in a split Grade 1/2 class explore and represent the sounds associated with city landmarks through soundscape composition. In particular, I focus on how students partake in the negotiation of identity. As a result of that, I have come to discover that by listening to children's soundscapes we may be able to feel something new about particular landmarks, contemplate its value to citizens, and learn more about the meaning making of children.
\end{abstract}

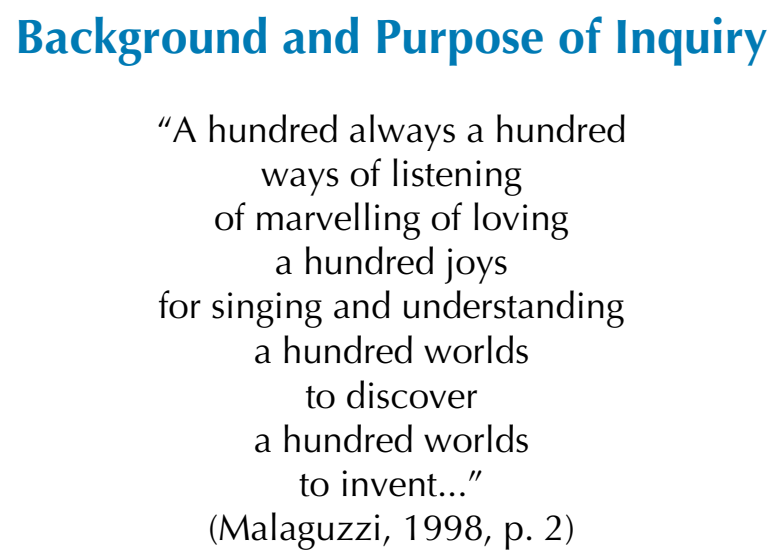

Educators within the municipally funded early childhood centers of Reggio Emilia provide their young learners with the means to develop multiple ways of thinking, speaking, loving, and understanding. Those concepts stem from a poem by Loris Malaguzzi (cited above), the founder of those centers. Malaguzzi not only advocates for child and teacher to engage with diverse media to express understanding, but also provokes an empowerment of children to express understanding through a medium of their choosing-including that of music.

The ideology that supports Malaguzzi's hundred languages is woven into the philosophies and practices of the ateliers of Reggio Emilia. For them, the atelier is a space that blends qualities of an art studio with that of a laboratory; it is a place for children to explore, create, and express using many artistic media, including pencils, markers, clay, recycled items, and photographs. As young learners interact with materials in the atelier, they are encouraged to explore the communicative possibilities of their creations, 
whereby they represent their plans, ideas, and understandings using one or more modes of expression. In that sense, the arts can be perceived as being "supraverbal," in that they involve expressive, nonsymbolic, and symbolic modes of thinking, understanding, knowing, and communicating ideas (Wright, 2012, p. 8) - they offer young learners a means to interpret and express an understanding of their world. Thereby when children engage with various media to illustrate understanding, they open doors to face new possibilities and generate new questions that would not have occurred had they used only one way of knowing (Forman, 1996, p. 172).

Over the course of the previous five years I have adapted many pedagogies and practices from the early childhood centers of Reggio Emilia. As a result of that, I have modified an elementary school music classroom to function as a Reggio Emilia inspired "music" atelier. ${ }^{1}$ In the music atelier, I am able to scaffold my students' understandings with musical provocations, co-learn alongside them, and empower them to explore and make music through traditional and nontraditional instruments, which in turn supports them in the development of a vivid musical language (Gouzouasis \& Yanko, 2018). In that context, the art studio is transformed into a music studio where visual arts media becomes music media, and incorporates the sounds of traditional musical instruments and those found in nature and the city. When children explore and create in the music atelier, the abstract nature of music encourages them to represent their understandings in a manner that significantly differs from the conventional methods available to them-they engage in a language of music.

In the atelier, the construction of knowledge is socially constructed and ever dynamic — children work with one another to explore multiple ways of expressing, demonstrating, and interpreting their understandings. They also become aware of themselves as questioners, meaning makers, and learners while engaging in the construction and reconstruction of realities with those around them (Greene, 1995, p. 130). Thus, as teachers, it is important for us to draw upon pedagogies and practices that scaffold such concepts, and communicate to students a notion that reality is made of multiple perspectives, never complete, and that there is always more.

"When students choose to view themselves in the midst of things and have the imagination to envision new things emerging, more and more beginnings seem possible." (Greene, 1995, p. 22)

Music may be considered the most abstract form of art, and it is astonishing to observe, listen, and co-learn with children as they engage their imaginations with music to expand beyond the possible. Students and teachers should not only be encouraged to illustrate understandings with music, but also reflect on it amongst the many conventional ways of communicating, as the arts provide a platform for children and teachers to see things in ways other than they are normally seen (Eisner, 2002, p. 83). A learning experience in Reggio Emilia that sought to understand the perception of children on their city brings to light such practices (Davoli \& Ferri, 2000). During this endeavor, a child with special needs was given an opportunity to engage with photographs, drawings, and sound materials to communicate his understanding of the city. His response focused on the sonic elements of his town, whereby he provided an example of a saxophone player performing on a street corner (Soncini, 2012). 
Inspired by that child's means of illustrating his understandings, in the current study I examine how children engage with music as media to express understanding. In particular, I focus on how children partake in the negotiation of identity. In doing so, I examine a project where students explore the sounds associated with city landmarks and co-compose soundscapes that illuminate the landmarks' importance and value. This study occurs over the course of three months and involves 20 students (ages 6-8) in a split Grade 1/2 class.

\section{Storying the Research Experience}

Different ways of knowing and communicating experiences through music is a fundamental aspect of this investigation. As such, engaging with impressionist qualitative methodologies can provoke "other" ways of knowing (Ellis, 2004, p. 39); specifically, ethnographic methods that enable storytelling can illustrate new ways of writing that reconceptualizes teaching and learning. The epistemology of story as method is that story is a way in which we tell ourselves to ourselves - we live storied lives. To bring light to how identity is negotiated in the city project, I employ an autoethnographic storying approach (Ellis, 2004), which empowers me to create stories written in a creative nonfictional style based on collected data from observations, notes, and artifacts. In doing so, I pursue "essences" and "meanings," rather than portraying and representing precise "facts" (p. 116)—as to autoethnographers, a truthful account is more important than a factual account (Gouzouasis \& Lee, 2002; Gouzouasis, 2008).

I present my experience of the city project using narrative elements to evoke a feeling that the described situation is lifelike and truthful (Ellis, 2004; Gouzouasis, 2008), while preserving the authenticity of it. I embrace a position that I am neither detached nor objective in my research position, as I not only draw from self-experience, but from those experiences I share with my students. To illustrate and elaborate multiple points of view and skillfully draw the reader into the story, I use various forms of voice (Gouzouasis, 2008). Autoethnography not only enables me to illuminate how the children imaginatively depict understanding through music, but also provides insights into the teacher's perspective.

\section{Grounding Literature}

When young learners engage in music making in the atelier, their interpretations are not only influenced by developmental characteristics, but also by the materials at hand. "The characteristics of the materials call up different conceptions and skills that function within the limits and possibilities of the material, and it is within the limits and possibilities of the material that cognition proceeds" (Eisner, 2002, p. 80). With that in mind, in this review I focus on research that examines children as they explore, express, and interpret with diverse musical elements to illustrate understanding.

Minimal research exists concerning children's views, perspectives, and accounts of the processes and products of compositional activity (Glover, 2000). However, studies by Moorhead and Pond (1941; 1942), Marsh (2000), and Sundin (1998), tend not to view data as something to be collected, measured, and tested, but as a social activity where children can creatively explore and learn. In reflecting on that, the research paradigm for the current study allows for contextual and situated understandings, 
as the ways in which children approach making learning visible with music must be flexible, open, and varied to encourage attentive creativity and heartfelt expression.

To examine multiple perspectives and co-learning, I turn to Eisner (2002), who elucidates that the arts celebrate multiple perspectives and that there are multiple ways to see and interpret the world (p. 83). Furthering that notion, I refer to Marsh (1995) who postulates, "Children's varying levels of understanding or skill may be accommodated and extended by this process of musical joint construction" (p. 7). I also draw from research by Burnard (2006) that illuminates how classmates can influence one another when engaged in composition, exploration, and music making, and Sangiorgio (2015) that shows how creating music in a group setting can enhance a child's sense of competence, ownership, and belonging. With that in mind, I strive to support and guide these young learners as they co-explore, co-construct, and negotiate understandings of their city through music.

As the children in this study partake in a co-construction of knowledge, they also partake in a negotiation of identity. To scaffold my inquiry into identity, I turn to the fourth stage of Erik Erikson's (1977) theory of psychosocial development, which centers on school-aged children. In that stage, the most significant relationship for children involves their school and neighbourhood - where teachers and classmates play an important role and parents are no longer viewed as complete authorities. It is a period where children begin to demonstrate specific competencies that are valued by society and begin to develop a sense of pride in their accomplishments (pp. 232-234). Taking Erickson's theory into account, the students in the current study actively and effectively negotiate their identities within a significantly complex space, that of the atelier where they co-construct knowledge with one another and the teacher.

As there are limits to written and visual understanding, music is able to provide the potential for new perspectives into human understanding (Gouzouasis, 2008). With that notion in mind, the students in this study are encouraged to engage with soundscape composition, inspired by Murray Schafer (1969; 1976), to elucidate the sonic environments of their city. The emergence of the soundscape in the 1960s was influenced by acoustic ecology and its focus on the interrelationship between sound, nature, and society (Westerkamp, 2002, p. 52), which correlates well with the students' city project. A soundscape composition contains recognizable environmental sounds that invoke listeners' associations, memories, and imaginations related to the soundscape. The original sounds must stay recognizable and the listener's contextual and symbolic associations should be invoked for a piece to be a soundscape composition (Truax, 2008, p. 105).

As the intent of a soundscape is to reveal a deeper level of signification inherent within the sound and invoke the listener's semantic associations without obliterating the sound's recognizability (Truax, 1995, p. 2), I believe it can encourage learners to not only reflect on their imaginative music-making abilities, but also empower them to develop a deeper connection and understanding of their city. Thus, as the children represent their theories through soundscape composition, they can begin to "re-know" and "re-cognise" them (Rinaldi, 2006, p. 50)—-they are able to make audible the intuitions, sounds, and experiences of their landmarks that take shape and evolve through action, emotion, expressiveness, and symbolic representations. 
Students are encouraged to notate their compositions and keep track of the musical elements and instruments involved. To scaffold that for young learners, I seek guidance from a study by Auh and Walker (1999) that examined student composition using traditional staff notation with nontraditional graphic notation and found that the use of nontraditional notation resulted in more musically creative compositions. As a result of that and the practices and pedagogies of the Reggio Emilia approach, the children in this study are encouraged to engage with diverse media to illustrate and keep track of their compositions_-drawings, pictures, musical notes, and words. In addition, Barrett (1999) found that when lyrics were introduced to kindergarten students' composition practices, they focused on the lyrics and minimal attention was given to the music. However, it can be argued that lyrics can bind a composition since children are already familiar with rhyme and story structures, and may be able to structure words sooner than music (Glover, 2000, p. 31). That being said, one group is arranging lyrics for a song instead of composing a soundscape.

\section{Music for Our City-Three Autoethnographic Vignettes}

As a means to illuminate the learning that unfolds and the negotiation of identity in the city project, I present three autoethnographic vignettes. The first story brings to light the learning process and negotiation of identity as the children engage in creating musical pieces about landmarks. The second vignette illuminates discourse that occurs between the students' classroom teacher and music teacher on the progress of the project, while the third depicts reflections by the learners on the entire experience.

Vignette one: Swimming pools, hockey rinks, and street signs. As the children work on their soundscapes, the sound of excitement catches my attention. I head over to three children sitting amongst a stack of percussion instruments.

"Wee - weee - weeee!" exclaims Louie waving his arms in the air, then suddenly stops and looks up at me.

"What's going on over here?"

"We are working on our swimming pool."

"The swimming pool? Why is that an important landmark?"

Justin replies, "Because it's a good place to learn to swim."

"It is useful to swim. If you get into trouble in the ocean you can swim or even save somebody else," adds Giovanna.

I prod a bit more, "Are you trying to show a specific pool in the city through your music?" Justin replies, "Canada Games Pool. That's where I swim. So far we have Louie saying weeee for people having fun and going down the whirly slide."

I notice a hand drum resting on the floor adjacent to Justin. "What are you using that for?"

"I want to make beats for splashes."

"That all sounds great so far. Have you thought about using the ocean drum?" 
"No, you mean that blue shaking drum? I'll go find it," Giovanna blurts as she runs off to a shelf full of instruments.

I leave them to continue their soundscape about the swimming pool and walk over to some students huddled over a bass xylophone.

"What are you working on?"

"Evelyn is showing us her part so we can learn it," Jessica replies.

"Can you show me how it sounds so far?"

Evelyn picks up a red yarn mallet and begins tapping a chromatic melody.

"Something like that but I don't know the next part, Casey is still creating it."

"The two of you are composing together?"

"No all of us are," Peter interrupts, "We all live in the same neighbourhood so we want the music to be from all of us."

"Can you tell me why you picked the neighbourhood as your landmark?"

Evelyn answers, "I know all of my neighbours and they are super nice. That's why it's my land ..."

Peter cuts in again, "My landmark is my house. If you don't have a home you would be homeless. A home keeps you safe and warm."

"Well, mine isn't our neighbourhood," Jessica pauses then continues, "it's the Capilano Street sign. I picked it because I live there. Street signs are important because they tell where you are."

The next class Calvin comes up to me and asks for help with his project.

"Mr. Yanko, Luisa and I are working on a school soundscape, but can't seem to find the right music."

"Well why did you pick school for your landmark?"

"Because your brain can develop more ideas there and you will become smarter."

I try to guide him toward a starting point, "What do you want to represent with your music?"

"We want music to show what we do at school to become smarter. So we need to create sounds for the start of the school day, recess, and lunch, but we don't know how to do that," he states with frustration.

"Well, let's start at the beginning. What happens at the start of the day?"

"We walk to school and unzip our backpacks and then do calendar."

"Ok how can we do that with music? What can we do for walking to school?" 
"Maybe we can stomp our feet," suggests Calvin as he shrugs his shoulders, then continues.

"Oh, we can also use the zippers on our backpacks for when we arrive."

"You see, you don't need instruments, you can also use your bodies or other objects."

I leave Calvin to work on his project and walk over to three boys at the piano. Two of them are singing and one is playing the piano.

"And then he shoots,

And then he shoots,

And then he shoots and scores."

"Have you found a hockey player yet for your song?" I interrupt.

Ricardo answers, "Joe Sakic because he's from here. My dad says that there is even a street named after him by the hockey rink."

"Can you remind me of your landmarks about sports?"

Scott replies, "I chose Lynn Valley because I play soccer there. It's important to me because if you don't play sports you might always be tired. Sports make you stronger."

Clint adds, "I chose the Vancouver Sports Complex. It was the first place I played sports at. It is special to me because I can play four sports there. Hockey, football, soccer and ..."

Ricardo finishes his sentence, “... and baseball. I chose Squint Lake because I play hockey there. There are a lot of ice rinks beside the lake. There's even a swimming pool, gym, and archery."

"How is your song coming along?"

"Well if I play the piano accompaniment by myself I making mistakes and have to stop, but when I play with them it is easier for me. They keep me going," Scott replies.

"You should pull apart the section that you keep on stopping at and practice it slowly many times until you feel comfortable with it. That may help. Can you tell me why you choose to write a song instead of doing a soundscape?"

Clint thoughtfully contributes, "We chose this song because I hear it at hockey all the time. I thought it would be easy to change the words to make it our own but it was hard." Ricardo adds, "It was hard to find new lyrics. The ones we came up with make you think about scoring lots of goals and being a champion like Joe Sakic."

Vignette two: Discourse between two educators. A few weeks of exploring, arranging, and practicing go by and we begin to record our compositions. One day during the recording process I stop by the students' classroom to touch base with their teacher, Jillian, about their progress. 
"How did the reflection part of their recordings go this afternoon?"

"I thought we would only get through one or two and that I would have to prompt them and do many takes, but things went smooth. These students are showing signs of confidence. I don't know where it is coming from," she replies.

"Perhaps it's from their recording experience with the soundscapes. We had to stop and rerecord things over and over because they weren't happy at times with the instruments and some of the harmonies were too loud. It took a long time to get the music the way they wanted."

Jillian continues, "The same thing is happening in my class, they are taking an ownership of the recording process. You should see the focus some of the students' put into their annunciations when recording their ideas of what can be added to improve the city. They really do have high standards for this project and thoughtful ideas of what new landmarks the city could use. There is merit to their ideas because they are founded on real issues they hear from the playground, their parents, or the news."

Vignette three: Reflection on the learning experience. After we finish recording the projects and share them with our community, the students and I gather to reflect on what they had learned. As we settle into our music atelier, the children gather in a semicircle shape, some take a seat on wooden stumps, while others sit on the carpeted floor. I begin the conversation.

"Through this project, I learned that all of you are very imaginative, that you can compromise with one another even if your musical ideas are different, that some of you had a keen ear for recording, and that with dedication and practice many of you were able to compose and play challenging music about your landmarks."

Justin cuts in without raising his hand, "I learned that the ocean drum sounds nice like the ocean," and Giovanna adds, "But not always, sometimes during the recording when you moved it too fast and hard it didn't sound the way we wanted it to, so we had to do it a few times until it was just right."

Samantha states, "I learned that you can make so many cool sounds with the top part of the flutes."

"You mean recorder," I correct.

"Yah, the flutes," she replies as I roll my eyes. "We made so many different chirps with it for bir..."

"Working with my group was hard because everyone had different ideas," Casey blurts out. 
Evelyn adds, "It's better to work with a group because you get more ideas and it's fun.

That's what I learned."

"A few of you played piano for the first time. Did anyone else learn anything about the piano?"

Scott answers, "Learning to play the song on the piano was fun. I don't take piano lessons so it

was fun to be able to learn a song for my friends." Clara immediately adds, "My piano song

took a lot of work. I had to practice it over and over and over again. It took me a million classes to learn the song and now it's stuck in my head." She begins to sing the pitches of her melody, "BB GG DD C ..."

"Singing was hard for me. It was hard to sing at the same time as Scott playing the piano.

It took a long time for us to sing and play together," Clint remarks.

"What did you learn about recording?"

"Not be goofy because we would have to start all over again. We had to be serious when recording," states Louie with a stern tone.

"The recording part was the best part of the project. It was fun to play the instruments and hear a recording of the music we made. Also, when we did the recording I didn't know that your voice sounds different when it is recorded," adds Krista.

Giovanna comments, "Yah, it was weird to hear myself sing because the recording was different from how I hear myself."

\section{An Exegesis on the Negotiation of Identity}

"Through the arts we learn to see what we had not noticed, to feel what we had not felt, and to employ forms of thinking that are indigenous to the arts." (Eisner, 2002, p. 12)

As children engage with instruments and materials in the music atelier, they persistently use unique representations as a means to frame their understandings of the world around them. Some research postulates that music can be viewed through a semiotic lens as a mode, or way of expressing knowledge (Tomlinson, 2013), whereby the engagement of a child in making music illuminates how music shares common semiotic processes with other modes of meaning making. While that may be the case, Reggio Emilia pedagogy elucidates that we need to move children beyond a level of making symbols into a level of inventing language (Forman \& Fyfe, 1998, pp. 248-249). Thus, the current investigation does not focus on critiquing the students' musical scores and recorded compositions, but examines how they frame, discuss, and reflect on music as a language for meaning making.

Learning experiences like those narrated in the present inquiry can have a substantial influence on how young learners negotiate and develop a sense of identity. As the students work with various media in the atelier to illustrate an understanding of particular landmarks, they begin to develop a routine that has a resemblance to the way people produce and reproduce their individual and collective identities: 
"being human-human being-ness-means to be creative in the sense of remaking the world for ourselves as we make and find our own place and identity" (Willis, 1990, p. 11). Therefore, the children not only engage in creatively portraying the essence of landmarks through soundscape composition, but they also partake in defining an identity of their own. In accordance with Erikson's (1977) theory of psychosocial development, a sense of identity amongst peers emerges as some of the students co-compose, negotiate, and teach one another a xylophone piece about a particular neighbourhood. Also, the participation in a routine of co-exploring, -composing, and -recording elucidates that in seeking to collectively make meaning, students are able to cultivate a supportive network within their learning community - one that empowers the development of the individual voice amongst others.

To be yourself is to be in process of creating a self, an identity. If it were not a process, there would be no surprise. The surprise comes along with being different-consciously different as one finds ways of acting on envisaged possibilities. (Greene, 1995, p. 20)

Participating in a learning community that fosters the individual voice among peers can encourage children to reflect on different perspectives-a reflection that involves embracing differences with a sensitivity to that what binds us together. Greene (1995) posits,

When we see and hear more we take risks into the unknown. We embark on new avenues for choosing and action where we may gain a sudden sense of new beginnings, and can take an initiative in the light of possibility. (p. 123)

Several children illustrate such ideas in the current study. For instance, Evelyn reflects on her appreciation for diverse musical ideas and sees them as an opportunity to voyage into new possibilities, while others, like Casey, struggle with compromising their opinions.

Although it can be a challenge, many students embrace listening as a way of welcoming others and their differences - a way of opening up to different theories and perspectives. As the students engage in a manner of reciprocal listening, they are able to represent their theories and interpretations through a medium of music, and in doing so they are also able to offer their peers the possibility of becoming part of their theories, developments, and thoughts (Rinaldi, 2004, p. 4). In particular, many of the students alter their listening abilities, resulting in them taking ownership of the recording process, whereby they stop the recording if a part is not in sync and rerecord it if words are not clearly enunciated or if the music is harmonically off. Furthermore, the dynamics between the three boys in the songwriting group depict an intricate and supportive relationship based on reciprocal listening, by which they collaborate to write lyrics and sing in tune while one of the boys accompanies on piano. Also, playing sports to grow stronger is a powerful message that could be hindered if portrayed through soundscape composition instead of song.

Deeper meaning making can occur when children engage in a process of music composition. However, when a final piece is shared with those not involved in the process, there should be some sort of resemblance that enables the listener to make a connection between the landmark and music written about it. For instance, the discussion with Calvin exemplifies that he is not only pondering the importance of his landmark to himself, but also attempting to illustrate how his composition enhances the listeners' 
connection to school_ "We want music to show what we do at school to become smarter." In addition, many of the children in this study are not only cognizant of a need to depict sounds associated with particular landmarks, but also illustrate an understanding of subjectivity and its effect on how music is co-composed and listened to.

\section{Moving Forward: Considerations for Practice}

"Listeners bring their own musical experience and understanding to what they are hearing, influenced by their personal and cultural musical biography. This understanding may be stretched or challenged by the unfamiliar, which then demands an effort of accommodation and an attempt to shift perspective in order to enter more fully into the musical experience and to understand it better."

(Glover, 2000, p. 22)

If we listen to children's soundscapes, we may be able to feel something new about particular landmarks, contemplate its value to citizens, and learn more about the meaning making of children. From this study, I have come to understand the value of pedagogy and practice that supports the negotiation of identity for young learners by enabling them to freely represent their own theories and interpretations. However, if teachers seek to guide students away from traditional means of music making to allow them to freely engage with their imaginations in abstract ways, they themselves need to be willing to venture into the unknown. This can be made possible by reimagining and retuning our ears to hone in on our listening skills so that we not only perceive ourselves in particular landmarks, but in the creative ideas, concepts, and offerings of our students.

The young learners in this study reveal the potential of music as a means to depict understandings of their world. Their engagement with music to make meaning illuminates the limitless possibilities of the hundred languages of music, and has triggered memories of my childhood to resurface. Much of my adolescence was spent with my grandparents who only spoke Italian. The means of communication between us mainly involved interpretation, gestures, patience, and love. When we attempted to communicate through spoken words, only a glimpse of what was meant was understood, and the true meaning was lost in language. Those memories remind me as to why the hundred languages of music is important for young learners. Since verbal language is often unable to clearly articulate abstract acoustical experiences, young learners need a means to imagine and illustrate their explorations, interpretations, understandings, joys, and love of music.

\section{Acknowledgment}

This research was produced with the support of a Social Sciences and Humanities Research Council (SSHRC) Doctoral Fellowship. I would like to thank Dr. Peter Gouzouasis for reading a version of this paper and providing helpful suggestions. 


\section{Note}

1. The ateliers of Reggio Emilia draw from the visual arts and tend not to employ elements of music.

\section{References}

Auh, M., \& Walker, R. (1999). Compositional strategies and musical creativity when composing with staff notations versus graphic notations among Korean students. Bulletin of the Council for Research in Music Education, 141, 2-9.

Barrett, M. (1999). Modal dissonance: An analysis of children's invented notations of known songs, original songs, and instrumental compositions. Bulletin of the Council for Research in Music Education, $141,14-20$.

Burnard, P. (2006). The individual and social worlds of children's musical creativity. In G.E. McPherson (Ed.), The child as musician. A handbook of musical development (pp. 353-374). New York, NY: Oxford University Press.

Davoli, M., \& Ferri, G. (Eds.). (2000). Reggio tutta: A guide to the city by the children. Reggio Emilia, Italy: Reggio Children.

Eisner, E. (2002). The arts and the creation of mind. New Haven, CT: Yale University Press.

Ellis, C. (2004). Autoethnographic I: A methodological novel about autoethnography. Walnut Creek, CA: Alta Mira Press.

Erikson, E. H. (1977). Childhood and society. London, UK: Paladin Grafton Books.

Forman, G. (1996). The project approach in Reggio Emilia. In C. T. Fosnot (Ed.), Constructivism: Theory, perspectives, and practice (pp. 172-181). New York, NY: Teachers College Press.

Forman, G., \& Fyfe, B. (1998). Negotiated learning through design, documentation, and discourse. In C. P. Edwards, L. Gandini, \& G. Forman (Eds.), The hundred languages of children: The Reggio Emilia approach - Advanced reflections (2nd ed.) (pp. 239-260). Greenwich, CT: Ablex.

Glover, J. (2000). Children composing 4-14. London, UK: Routledge.

Gouzouasis, P. (2008). Toccata on assessment, validity, and interpretation. In S. Springgay, R.L. Irwin, P. Gouzouasis, \& C. Leggo (Eds.), Being with a/r/t/ography (pp. 219-230). Rotterdam, NL: Sense Publishers.

Gouzouasis, P., \& K.V. Lee. (2002). Do you hear what I hear? Musicians composing the truth. Teacher Education Quarterly, 29(4), 125-141.

Gouzouasis, P., \& Yanko, M. (2018). Reggio's arpeggio: Becoming pedagogical through autoethnography. In W. Parnell \& J.M. Iorio (Eds.), Meaning making in early childhood research: Pedagogies and the personal (pp. 56-70). New York, NY: Routledge.

Greene, M. (1995). Releasing the imagination. San Francisco, CA: Jossey-Bass Publishers. 
Malaguzzi, L. (1998). No way. The hundred is there. In C. P. Edwards, L. Gandini, \& G. Forman (Eds.), The hundred languages of children: The Reggio Emilia approach - Advanced reflections (2nd ed.) (pp. 2-3). Greenwich, CT: Ablex.

Marsh, K. (1995). Children's singing games: Composition in the playground? Research Studies in Music Education, 4, 2-11.

Marsh, K. (2000). The composers in the playground. Paper presented at the Creativity Special Research Interest Group session, Music Educators National Conference, Washington, DC, 8-11 March.

Moorhead, G., \& Pond, D. (1941). Music of young children: I. Chant. Pillsbury Foundation Studies. Santa Barbara, CA: Pillsbury Foundation for Advancement of Music Education.

Moorhead, G., \& Pond, D. (1942). Music of young children. II. General Observations. Pillsbury Foundation Studies. Santa Barbara, CA: Pillsbury Foundation for Advancement of Music Education.

Rinaldi, C. (2004). The relationship between documentation and assessment. Innovations in Early Education: The International Reggio Exchange, 11(1), 1-4.

Rinaldi, C. (2006). In Dialogue with Reggio Emilia: Listening, researching and learning. London, UK: Routledge.

Sangiorgio, A. (2015). Collaborative creativity in music education: Children's interactions in group creative music making. (Unpublished Doctoral Dissertation, University of Exeter).

Schafer. R. M. (1969). The new soundscape: A handbook for the modern music teacher. Don Mills, ON: BMI Canada Limited.

Schafer, R. M. (1976). Exploring the new soundscape. Unesco Courier, XXIX, 4-8.

Soncini, I. (2012). The inclusive community. In C. P. Edwards, L. Gandini, \& G. E. Forman (Eds.), The hundred languages of children: The Reggio Emilia experience in transformation (3rd ed.) (pp. 187-212). Santa Barbara, CA: Praeger.

Sundin, B. (1998). Musical creativity in the first six years. In B. Sundin, G. McPherson, \& G. Folkestad (Eds.), Children composing (pp. 35-56). Malmö, Sweden: Malmö Academy of Music, Lund University.

Tomlinson, M. M. (2013). Literacy and music in early childhood: Multimodal learning and design. SAGE Open, 3(3), 1-10.

Truax, B. (1995). Sound in context: Soundscape research and composition at Simon Fraser University. Proceedings of the International Computer Music Association, 1-4.

Truax, B. (2008). Soundscape composition as global music: Electroacoustic music as soundscape. Organised Sound, 13(2), 103-109.

Westerkamp, H. (2002). Linking soundscape composition and acoustic ecology. Organised Sound, 7(1), 51-56.

Willis, P. (1990). Common culture: Symbolic work at play in the everyday cultures of the young. Milton Keynes, UK: Open University Press.

Wright, S. (Ed.). (2012). Children, meaning-making and the arts (2nd ed.). Frenchs Forest: Pearson Education Australia. 


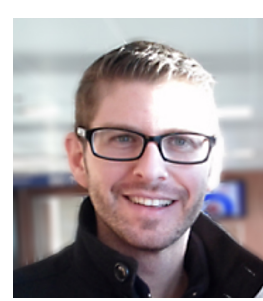

Matthew Yanko is a doctoral candidate in the Department of Curriculum and Pedagogy at the University of British Columbia. Under the supervision of Professor Peter Gouzouasis, his research focuses on formative assessment practices in music education. Inspired by the early childhood centers of Reggio Emilia, Matthew has adapted this approach to his elementary school music classroom, which has inspired the creation of a musical atelier for his students to participate in music making, learning, and inquiry. 